\title{
Arbor
}

\section{Mujeres en música}

\section{Mary Cruz Galatas}

Arbor CLXVIII, 663 (Marzo 2001), 425-433 pp.

Decía Gulda, uno de los más famosos pianistas del siglo XX en su libro de Oro de la regla de tres que «a la música y al amor no se les descubre, se les siente».

Creo que sentí la música desde el primer día que nací... Pues lo hice chillando y cantando fuerte y aún sigo redescubriendo la música continuamente, desde el piar de cualquier pájaro extraño, hasta el sonido del vapor del agua.

Es muy posible que esté un tanto contaminada por la música y sus vibraciones, pues siento que mis poros y mis moléculas la respiran.

Daniel Pineda Novo, Catedrático de la Universidad de Sevilla, comentó no hace mucho al analizar mi libro «Atmósferas Silábicas en Anacrusa» que sentía la poesía y poseía una musicalidad capaz de conciliar las dos cosas. En realidad tardé varios años en darme cuenta de que tenía esta dualidad. Pasaron varios días e incluso meses y han estado mis pentagramas adormecidos por las letras de uno de mis libros ,uno muy especial, y sentí que no podía componer y escribir poemas casi en una misma tarde, necesitaba hacer el vacio de nuevo en el cerebro y dejar pasar unas horas entre una cosa y otra.

Hoy en estas líneas selecionaré algunas mujeres un tanto curiosas y muy especiales en el mundo de la Música. Citaré a Santa Cecilia, a Sofía Vela, descubierta por mí después de asistir a una conferencia del Historiador Matías Diaz Padron; también incluiré una compositora actual: Consuelo Diez.

\section{HAIKU}

Esas notas perfumadas

Envuelven una

Aromática sinfonía. 


\title{
Mary Cruz Galatas
}

\author{
Mis dedos caen sobre \\ unas cuantas notas. \\ $Y$ van cediendo. \\ Piano, pianissimo. \\ A modo d'amore.
}

En marfil de teclas.

He de decir que me cuesta bastante hablar sobre mi obra musical o mi obra poética. Varios críticos a lo largo de mi trayectoria musical lo han hecho, entre ellos Enrique Franco, Andrés Ruiz Tarazona, José Luis del Busto, Pérez de Arteaga, Angel García López, etc. Pero en estos días me ha insistido tanto mi amiga Carmen que no he tenido más remedio que incluir una página sobre mí en este breve trabajo sobre «Mujeres en Música».

\section{Santa Cecilia}

A fines del siglo XV es cuando se puede considerar a santa Cecilia como patrona de la Música, aunque ella no llegó a tocar el piano, sí cantaba y se acompañaba tañendo al órgano en muchas ocasiones, por eso hay tantos y tantos retratos en actitud musical sobre su arte y bondad y afamados pintores plasmaron su imagen a lo largo de los años, citemos a Rafael a Rubens y al famoso cuadro de Possin.,que está ahora en el Museo del Prado. Otro famosísimo cuadro del tema de Santa Cecilia está pintado de la mano de Michel Coxie y en la actualidad se conservan dos versiones, una en Las Descalzas Reales y otra procedente del Escorial que se conserva en el Museo del Prado. Michell Coxie fue un pintor originario de las Malinasss y es uno de los artistas flamencos más claramente romanizados del siglo XVI y fue uno de los pintores más apreciados de la familia de Habsburgo pues Carlos V le encargo muchas obras. Su cuadro de Santa Cecilia fue enviado por el Rey Felipe II a la Iglesia vieja del Monasterio del Escorial en Abril de 1574 y más adelante pasó al Prado el 18 de noviembre de 1574; en el cuadro destacan los niños y los ángeles músicos que rodean a Santa Cecila. Está firmado en el clavicordio. Sus medidas son de 1,36 x 104. Óleo sobre tabla.

En Inglaterra muchos músicos de todos los tiempos le rindieron homenaje componiéndole música en varias ocasiones. Citaré:

Henry Purcell compuso dos «Odas a Santa Cecilia» (1683).

Haendel y Boyce, que la inmortalizaron igualmente componiendo dos obras magníficas. 


\section{Mujeres en música}

Entonada por el genial compositor, Haendel y Boyce la inmortalizaron igualmente Huert Parry y el organista romántico Samuel Wesley.

En Francia cabe destacar la preciosa «Misa de Santa Cecilia» que Gounoud escribió con motivo de la celebración en París del 22 de Noviembre.

En Italia, su país de origen, viene siendo venerada como patrona de la Música desde el siglo XVI ya que en 1585 el Papa Sixto V, aprobó la constitución de la Congregación de Santa Cecilia. EE.

Allessandro Scarlatti le dedica una preciosísima «Misa a Santa Cecilia» en 1720.

En España el guipuzcoano Padre Nemesio Otaño (1880-1956) es autor de un Cantatibus organi»

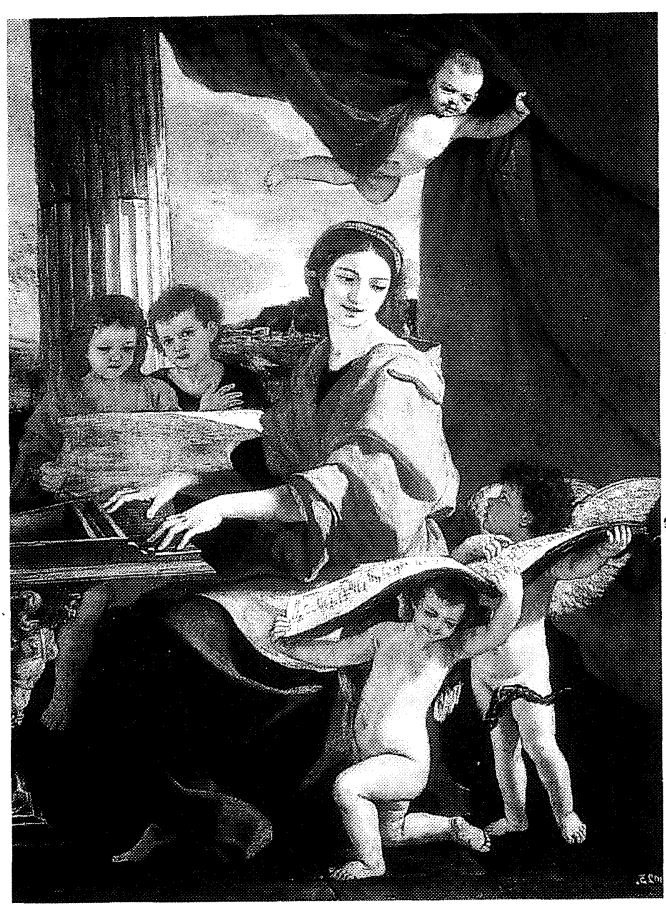

Santa Cecilia. en honor a la Santa; también el compositor madrileño Francisco Calés (1925-1985) obtuvo con una cantata del mismo título, para solistas, coro mixto y orquesta, El premio nacional de Música de 1954.

Algunos historiadores creen en realidad que santa Cecilia, vivía ofrecida a Dios y dedicada a los demás.

Que pertenecia al linaje de los Cecilíos « gens Cecilia. Plutarco en «Vidas Paralelas» comenta que además de su gran belleza, cultivaba las letras, tocaba muy bien la lira, y estudiaba geometría además de proponer cuestiones filosóficas.

Le casa el Papa Urbano y eligen como esposo a Valeriano y le dijo la santa claramente: «Que su corazón y su carne permanecerían puros siempre».

Los historiadores cuentan que así fue y que un ángel apareció el día de su noche de bodas e inmediatamente después Valeriano se convirtió a la Fe de Cristo. Viviendo con una túnica blanca de color de nieve junto a su esposa Cecilia hasta que fue degollado por orden de Máximo y su viuda recogió su Cuerpo, lo mando embalsamar y permanece en las catacumbas de Pretextato.

Ella solía tocar la lira y estaba absorta en la oración entre melodía de arpas y címbalos. 
Sus enemigos quisieron asfixiarla y la encerraron en el "caldearium» pero todavía respiraba a la segunda noche del martirio; a continuación decidieron decapitarla, interviniendo el verdugo que lo hizo con tres golpes, permaneciendo envuelta en su propia sangre apacible y con sus manos entrelazadas.

Está representada por Maderna en una estatua yacente de blanquísimo mármol sobre el altar Mayor de una basílica romana, construida sobre el palacio que perteneció a los esposos.

\section{Sofía Vela y Querol}

Sofía Vela fue una estupenda cantante, además de pianista y compositora, y participó con cierta frecuencia en las funciones del Liceo Literario de Madrid desde 1848.

En 1850 fue Federico Madrazo, en un retrato muy elocuente y casi mágico, el que la retrató y precisamente al verlo me hizo descubrir su existencia como gran cantante y su personalidad.

Sofía fue muy amiga de la familia Madrazo y ella y su marido Antonio Arnao pasaban muchas veladas en casa de los Madrazo. En 1851 fue designada contralto de la Real Cámara de Madrid interpretando para Isabel II las cuatro óperas que se representaron en el Palacio Real de Madrid entre 1849 y 1859: Luisa Miller de Verdi, La Straniera de Bellini Ildeconda y la conquista de Granada de Arrieta, joven compositor bilbaíno.

Un compositor famoso de entonces le dedicó su sonata n. ${ }^{\circ} 1$ para piano. (Francisco Asís de la Peña).

Más adelante Arrieta le dedicó en una carta en 1887 su más famosa opera Marina.

De su labor como compositora cabe destacar algunas obras religiosas como las tituladas «Memorare». "Miserere al Santísimo Cristo de la Salud, Flores a María, Camino del Cielo, entre otras muchas obras de la compositora Sofia Vela.

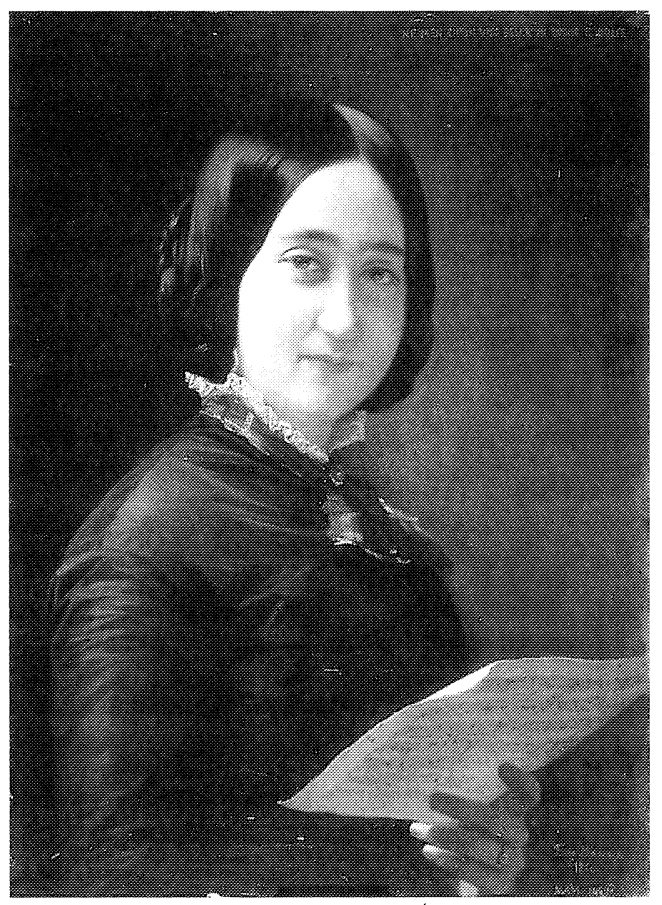

Sofía Vela y Querol. 
Cabe destacar la elocuente dedicatoria en Italiano que le dedicó a la famosa Sofía el pintor Madrazo: «Tan bello es su rostro como dulce su voz...»

El retrato de Madrazo es bellísimo y es uno de sus retratos más sutiles y delicados en el tratamiento de la iluminacion. Dirigida desde la izquierda hacia la modelo y manejada espléndidamente en sus múltiples efectos. En el retrato permanece en penumbra el lado contrario tenuemente matizado por la reverberacion del blanco de la partitura que sostiene la cantante en la mano, y cuya delgadez mágica hace que pase la luz en el papel, El esbozo de su sonrisa en el cuadro nos recuerda al gran pintor italiano Leonardo.

En fín Pompey un gran hisstoriador de aquella época hace un extenso comentario sobre el cuadro y al final lo define como «un poema de amor y misterio...».

Este famoso cuadro se puede contemplar en el Museo del Prado de Madrid es un óleo sobre lienzo y mide $0,62 \times 0,50$.

\section{Consuelo Diez}

Destacaré en este artículo sobre mujeres en la Música a una gran compositora, Consuelo Díez. Actualmente es directora del Centro para la Difusion de la Música Contemporánea INAEM y es una gran impulsora de la música electroacústica en España y en muchos países Europeos. Sus obras se han inerpretado en Francia, Italia, Dinamarca Austria Bélgica y Gran Bretaña entre otros países del globo. Ha dirigido durante varios años el programa «EL canto de los adolescentes. «Sobre Música Electroacústica en RNE-RADIO 2 y es responsable de LINCE-CAM desde 1988».

También ha colaborado en libros y escrito numerosos artículos para revistas especializadas en Música.

Su obra es extensa y destacaremos:

En 1999 recibió el premio «Viva el Espectáculo» en Alicante.

Entre su discografía destacaré:

«NAGGARETH» CD: 1989

«VIDA» Presencia de LUIGI NONO. 1992,

«SABOR A CRISTAL» 1994.

«SAXO, MENTIRAS Y CINTAS DE AUDIO». 1998.

Consuelo en la actualidad tiene un gran prestigio como directora y lo que es más como compositora.

Empezó siendo pianista y de pronto se le iluminó el «chip» y dijo a sus compañeras de carrera "yo en verdad me decido por la composición... y en poco tiempo ha logrado la cúspide. 
Actualmente es la elegida por la Universidad de Alcalá de Henares para hacer una composición Cervantina sobre el genial autor.

Testimonio de una alumna compositora de Maurice Ravel

En este otro capítulo mencionaré a una alumna fantástica que tuvo Ravel en San Juan de Luz y que aunque paso al anonimato escribió, muchas historias sobre Ravel y lo admiró montones. Esto fue escrito en los años sesenta y se encontró en Francia.

«Es posible que alguna página pase al olvido o que se pierda» comentaba la autora al principio de una de sus partituras de papel pautado en rayas de música. Era un maravilloso vals senza rigore da tempo y siempre escrito en $3 / 4$.

$\mathrm{Al}$ escuchar esa su melodía increíble se capta ese halo fantasmagórico que llevan sus melodías atrevidas.

$\mathrm{Y}$ sus alumnos comprendemos esos susurros colmados de belleza y sentidos con desvelo y revividos en ocasiones sin remordimiento alguno frente a la sociedad que en veces no le coomprendió.

$\mathrm{Su}$ afable fantome como el le solía decir... termina cautivo «dans le tombeau» aunque envuelto por notas de marfil amorosas...

\section{Leonora Mindelburg, «Leonora»}

Gustav Klimt ,famoso pintor Vienés tuvo como modelo casi exclusiva a lo largo de su vida a la famosa y voluptuosa modelo Eleonora, mujer pelirroja que aparece en sus más famosos cuadros,ella encarnaba ese Ideal femenino de su época y fue además la musa exclusiva de Klimt. Leonora Mindelburg, pianista y compositora encarna un ideal de belleza que surgió de la fusión de los colores procedentes de la magnífica paleta de Klimt y la increíble música del maestro Mahler.

A lo largo de su vida escribió unas nueve sinfonías algunas sin terminar. Su primeraa sinfonía tenía por título «Juegos de Agua» y el piano tenia a lo largo de la obra un gran protagonismo.

Leonora terminó una de sus sinfonías en el año 1917 y su deseo por aquel entonces fue que se estranase unos años después de su muerte. Eso le hacia pensar en su continuidad...

Su cuarta sinfonía es la más escalofriante de sus obras, daba la sensacioon de tristeza en momentos y en otros reflejaba desconfianza. En su primer movimiento se percibe el piano de manera sideral, y en el segundo movimiento destaca un bellisimo sherzo Ella fue admirada a principios del siglo en la ciudad de Viena, donde los intelectuales los artistas y los compositores desplegaban un gran fervor creativo. 
Verdaderamente esta mujer tan singular y creadora fue para muchos una eterna sorpresa.

Ella encarnaba el ideal femenino de su época en Viena, y fue la mejor musa del genial pintor Klimt.

Su obra musical fue descubierta unos cuantos años después de que falleciese. Ya que ella en vida ella lo dispuso así.

\section{Mary Cruz Galatas}

Para componer hay que tener un equilibrio de mente y al mismo tiempo encontrar ese silencio buscado envuelto de una especie de vacío y así continuar con la idea y de alguna manera dar paso a la inspiración.

Antes de ser compositora yo quería ser médico o trapecista, pero mi madre se empeñó en que tenía que ser pianista y me llevó a dar clase de solfeo y piano con Mili Porta, profesora fantástica de solfeo y piano, que me fascinó y empecé la carrera de piano sin parar, simultaneando con el bachillerato. Terminé los estudios de piano en el Conservatorio de Música de Madrid, y a partir de 1978 actué como concertista dando recitales y conciertos por toda la península y, en el extranjero, en Manila, Bangkok, Santo Domingo y Guayaquil, destacando mi actuación en el Teatro Principal de Santo Domingo, en 1981, donde me dí a conocer como compositora.

Ser compositora e intérprete de música es algo muy serio, y a la vez es sentir algo muy especial y satisfactorio después de haber trabajado durante años, se recogen los frutos en una de las carreras más peliagudas, porque dependes de la crítica, del público y de la captación de tu música..

En una ocasión: le dije a una profesora Madame Favre de pia-

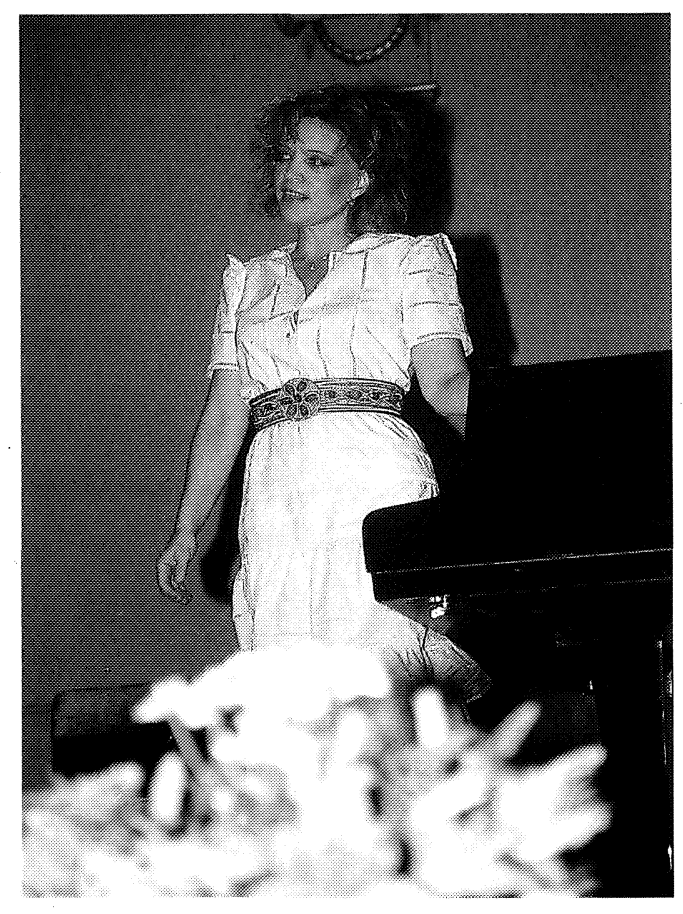

Mary Cruz Galatas en uno de sus conciertos. 
no (en Suiza) «no haré las correcciones que me propone madame sobre la obra de Sevilla de Albéniz me la estudié en España y es allí donde mejor se capta a sus autores y Uds. aquí en Suiza no saben lo que es lo español y flamenco. Era muy pequeña y recuerdo que costó una buena reprimenda.

Música os cogerá casi todo el tiempo del mundo pero si os volcáis siempre el piano os responderá.

Mi música se relaciona en veces con la Pintura puesto que me han llegado a inspirar varios pintores al contemplar algunos de sus cuadros como es el caso de Roberto Domingo, Goya Chu-lily, Montero etc...

Realiza grabaciones de su obra para R:N:E-RADIO 2. Television Catalan, ETB. J:C:J:K. Emisora Musical colombiana.

En un momento dado de mi vida empiezo a escribir Poesía 1990 destacaré algún libro: En Soria Almas. De Claustro-(1992) Ráfagas del Sur y Norte. (1993) Rimas en Flor (1994) Haikus en Bemoles (1996). Con Roberto Domingo (1999) Adibu, Adibú, etc. Colombiana y tiene en la actualidad dos compacts., de su obra pianística. $\mathrm{Y}$ otro $\mathrm{cD}$. para voces piano $\mathrm{y}$ efectos electroacústicos.

\section{Anécdotas de una compositora}

En el año 1982 el Centro Colón de Madrid estrené mi primera obra para piano, percusión y efectos electroacústicos. La dediqué a Ernesto Hallfter; la sala estaba a tope de compositores y justo cinco minutos antes de estrenar, la partitura se me perdió; entonces, el percusionista Carlos de Castro, después de estar buscándola durante tres minutos en el camerino, encontró la fotocopia y pude estrenar con éxito.

En 1983 me encargó el S.I.MO. «ELECTRÓN CX-84». Cuatro meses antes me pasé coleccionando llaves para lanzarlas en mogollón por el escenario -el día del estreno-.

En Anwert, me pilló una manifestación, y con mi despiste, me dirigí media hora antes de empezar a otra sala; tuve la suerte que el señor que me presentaba se alargó en el tema un poco, y llegué justísima.

En New York, el día en que estrenaba en el Carnegie Hall -Dual Vibrations-, por la maña tenía un piano que no era el adecuado; le dije a mi representante que me lo cambiaran o que no estrenaba. Efectivamente, me trajeron un piano de la casa Steinway y salió perfecto.

En los Altos de Maimona, en el año 1983, no llegaba el camión que traía el piano a la iglesia principal, y cuando llegó, faltaba la llave para abrir el teclado... Tuvo que volver el camión a Cáceres y empezó el concierto con dos horas de retraso, por motivos de mala organización. 


\title{
Haiku en el tren: \\ Avanza el paisaje. \\ Glisando en tren. \\ Se divisan rebaños.
}

Casi siempre me gusta subirme a un tren, se dsifruta del paisaje muy cómodamente te dan ganas de re-pensar.

Algunas personas sueñan y otras dormitan sin más a lo largo del recorrido.

Algunos conocidos compositores se han inspirado en los ruidos de las máquinas del tren. $\mathrm{E}$ incluso en el chirrido de los ruidos de sus ruedas. Cuando la vía está casi perfecta en muchos trenes se siente la sensación de ir como deslizandote.

A mí me recuerda el glissando que me producían los patines de cuchillas para ir deslizandote por la pista de hielo, solo que el del ferrocaril se hace sin el esfuerzo físico...

Los personajes que te encuentras en un tren son de lo más variopintos.

$\mathrm{Al}$ encontrarme un día con una amiga al borde de la depre le aconsejé subirse en un tren y dejarse llevar.

$Y$ fue estupendo para ella encontrar a la persona ad hoc para su estado de ánimo y tan es así que al cabo de los años decidieron formar pareja.

Uno de mis últimos viajes en tren un pasajero me dijo algo muy curioso: Este tren talgo supera las traviesas como las cuentas de un rosario.

\author{
Yo añadiria un Haiku. \\ Vamos a toda maquina. \\ Avanza el paisaje en glisando. \\ Se divisan rebaños que pacen. \\ Música de fondo, un niño grita. \\ Despierta un viajero... \\ $Y$ se apea en burgos.
}

Muchos terminan sus vacaciones en un tren y se replatean una vida distinta...

También es muy posible entablar una agradable consversación durante un viaje de más de dos horas. E incluso se dan casos de encontrar la pareja adecuada en un recorrido. 